\title{
Sebaran Intrusi Air Laut di Kabupaten Indramayu, Jawa Barat
}

\author{
(Distribution of Seawater Intrusion in Indramayu District, West Java)
}

\author{
Ahmad Abdul Hafiidh ${ }^{1 *}$, Satyanto Krido Saptomo ${ }^{1}$, Chusnul Arif ${ }^{1}$ dan Roh Santoso Budi \\ Waspodo ${ }^{1}$
}

${ }^{1}$ Departemen Teknik Sipil dan Lingkungan, Fakultas Teknologi Pertanian, Institut Pertanian Bogor
Jl. Raya Dramaga, Kampus IPB Dramaga, PO BOX 220, Bogor, Jawa Barat Indonesia

Penulis Korespondensi: ahmadabdulhafid@gmail.com

Diterima: 31 Juli 2017

Disetujui: 27 Agustus 2018

\begin{abstract}
Indramayu District is the widest area as rice producer in Java Island. Most of Indramayu Regency is located in coastal areas, so that groundwater becomes a much-needed resource for agricultural irrigation. Ongoing exploitation and increasing volume over time cause the formation of empty space in the aquifer layer so that the empty space on the ground is then filled by sea water. In this study Artificial Neural Network (ANN) is used to predict water intrusion. The objective of the study was to determine the intrusion-based zonation map based on groundwater quality, for exemple total dissolved solid (TDS) and electrical conductivity (EC). The study was conducted in 33 sub-districts with 83 sampling points in February 2017. The rice field in Indramayu District is extend about 57.94\%, with contours of lowland and sediment areas in the northeast. Indramayu District surface water supply comes from Cimanuk, Cipunegara and Cipanas watersheds. In the dry season the ground water of Indramayu District has been over-exploited for the wells as irrigation. The free aquifer is located 3 - 30 meters below ground level, with a thickness of about $15-20$ meters, flowing from south to north. Topography of Indramayu District is at an altitude of 0-100 meters above sea level with an average slope of 0-2\%. This is causes the District Indramayu flooded water during high rainfall. Groundwater quality values are obtained that the northern and eastern sections are larger than the south because the coastal boundaries are located in the north and east.
\end{abstract}

Keywords: EC, Indramayu District, intrusion, TDS

\section{PENDAHULUAN}

Air merupakan sumberdaya yang melimpah di bumi dimana bumi tertutupi air sebesar $71 \%$, dan jumlah air baku hanya sebesar $2.8 \%$. Air baku terdiri dari $70 \%$ berbentuk kutub dan sisanya sebagai airtanah. Kebutuhan air untuk irigasi merupakan salah satu pemanfaatan sumberdaya airtanah. Sumberdaya air permukaan menjadi salah satu andalan penyediaan air irigasi. Akan tetapi sebagian daerah pertanian tidak mendapatkan irigasi dari waduk (Waspodo, 2015).

Wilayah terluas sebagai penghasil beras di Pulau Jawa adalah Kabupaten
Indramayu. Sebagian besar Kabupaten Indramayu berada di daerah pesisir pantai. Oleh karena itu, airtanah menjadi sumberdaya yang sangat dibutuhkan untuk irigasi pertanian. Akan tetapi eksplorasi airtanah yang berlebihan menjadi salah satu faktor terjadinya intrusi air laut (Suhartono, 2012).

Proses masuknya air laut ke dalam aliran airtanah merupakan pengertian intrusi air laut (Ayolabi, 2013). Eksploitasi yang berlangsung secara terus menerus dan volum yang semakin meningkat dari waktu ke waktu menyebabkan terbentuknya ruang kosong di lapisan akuifer sehingga ruang kosong 
pada tanah kemudian diisi oleh air laut (Werner, 2013).

Penelitian menggunakan parameter utama yang dapat membedakan air tawar, payau dan asin adalah TDS dan EC. Total Dissolved Solid (TDS) adalah mineral, garam, logam dan kation - anion yang terlarut di air. Benda padat yang terlarut dibagi menjadi organik dan anorganik. Electrical Conductivity adalah kemampuan zat cair untuk menghantarkan arus listrik. Parameter tersebut adalah parameter utama dalam penentuan intrusi air laut.

Tujuan dari penelitian untuk menentukan peta zonasi intrusi. Penelitian diharapkan dapat memudahkan masyarakat untuk menentukan daerah akuifer yang tidak terkena intrusi. Mengatasi permasalahan ini perlu adanya adanya pemetaan terhadap intrusi air laut berdasarkan parameter kualitas airtanah yang terdiri dari Total Dissolved Solid (TDS) dan electrical conductivity (EC).

\section{BAHAN DAN METODE}

Penelitian dilakukan di Kabupaten Indramayu yang terletak pada koordinat $107^{\circ} 52^{\prime}-108^{\circ} 36^{\prime}$ BT dan $6^{\circ} 15^{\prime}-6^{\circ} 40^{\prime}$ LS pada bulan Februari 2017. Pengambilan data diperoleh dengan pengambilan data primer dan data sekunder. Perlengkapan yang diperlukan terdiri atas, multimeter dan kabel, GPS Garmin 64s, alat ukur kualitas air AMTAST AMTO3R, alat ukur $p H ~ P H-$ 009(1)A dan seperangkat komputer dilengkapi software surfer 10.0 dan Microsoft office 2007.

Tahapan penelitian terdiri atas tahapan pengumpulan data primer dan data sekunder. Data primer didapat dengan pengambilan nilai TDS dan EC di 83 titik sampling pada 33 kecamatan. Data sekunder diperoleh dengan mengumpulkan data penunjang berupa peta administrasi, peta topografi, peta tata guna lahan, peta geologi, peta hidrogeologi dan pengumpulan literatur penunjang.

Data sekunder merupakan data penunjang untuk penentuan lokasi titik sampling. Data primer berupa nilai TDS dan EC yang telah didapatkan diolah menggunankan model Jaringan Saraf Tiruan (JST). Jaringan saraf tiruan terdiri dari input layer, hidden layer dan output layer. Lapisan masukan (input layer) terdiri dari titik sampling koordinat $\mathrm{X}$, koordinat $\mathrm{Y}$, kedalaman sumur dan elevasi. Lapisan tersembunyi (hidden layer) merupakan hasil dari pemodelan menggunakan JST. Lapisan keluaran (output layer) terdiri dari nilai TDS dan EC seperti Gambar 1.

Hasil dari parameter yang didapatkan (TDS dan EC) kemudian di

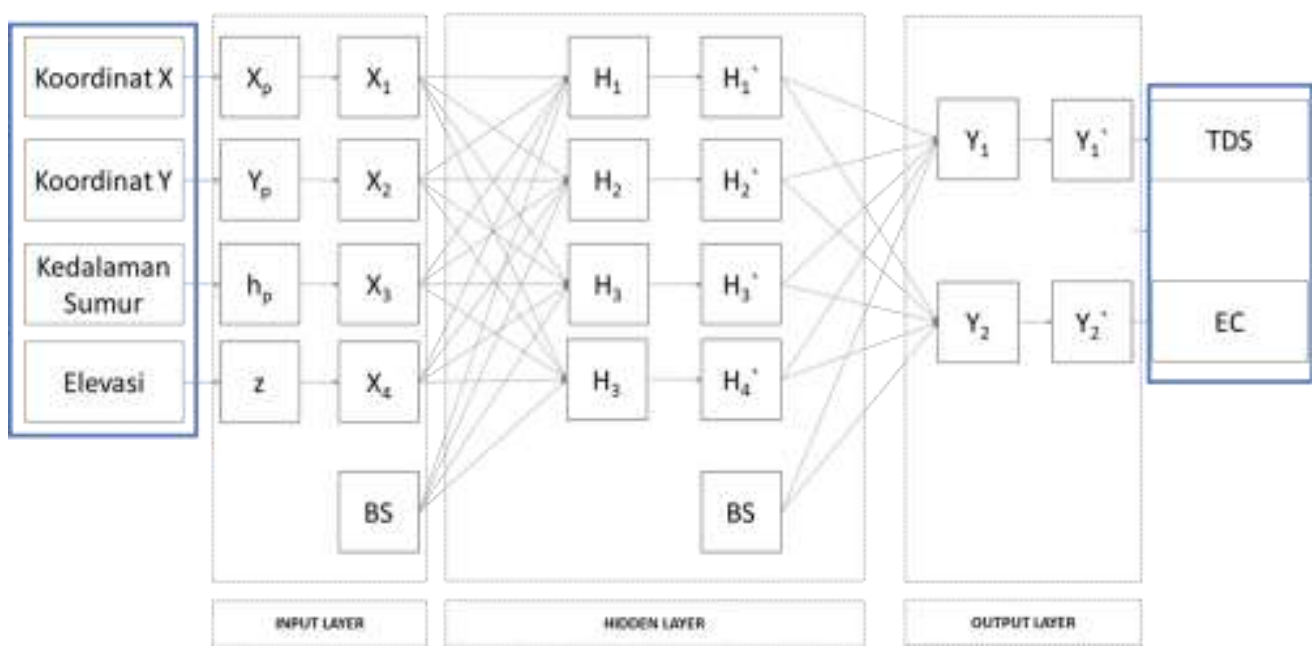

Gambar 1 Model JST yang Dikembangkan 
overlay ke peta administrasi. Parameter utama yang dapat membedakan air tawar, payau dan asin adalah nilai TDS dan EC. Klasifikasi tingkat keasinan airtanah menurut Keputusan Panitia Ad Hoc Intrusi Air Asin (PAHIAA) 1986 (Sihwanto, 1991) seperti pada Tabel 1.

Tabel 1 Klasifikasi tingkat keasinan airtanah

\begin{tabular}{ccc}
\hline Kualitas & TDS $(\mathrm{mg} / \mathrm{L})$ & DHL $(\mu \mathrm{mhos} / \mathrm{cm})$ \\
\hline Tawar & $<1000$ & $<1500$ \\
Agak Payau & $1000-3000$ & $1500-5000$ \\
Payau & $3000-10000$ & $5000-15000$ \\
Asin & $10000-35000$ & $15000-50000$ \\
Brine & $>35000$ & $>50000$ \\
\hline
\end{tabular}

\section{HASIL DAN PEMBAHASAN}

\section{Topografi Indramayu}

Kabupaten Indramayu berbentuk dataran rendah dan memiliki topografi pada ketinggian $0-100$ meter diatas permukaan laut (Tabel 2).

Kabupaten Indramayu memiliki kemiringan rata rata $0-2 \%$. Hal tersebut mengakibatkan Kabupaten Indramayu akan tergenang air jika curah hujan tinggi.
Tabel 2 Topografi Kabupaten Indramayu

\begin{tabular}{cl}
$\begin{array}{c}\text { Ketinggian } \\
(\text { mdpl })\end{array}$ & \multicolumn{1}{c}{ Kecamatan } \\
& \multicolumn{1}{c}{ Anjatan, Sukra, Patrol, } \\
& Kandanghaur, Losarang, Sindang, \\
& Lohbener, Arahan, Cantigi, \\
& Pasekan, Indramayu, Balongan, \\
& Juntinyuat, Sliyeg, \\
& Kedokanbunder, Krangkang, \\
& Karangampel \\
& Bongas, Kroya, Gabuswetan, \\
& sebagian kecamatan Anjatan, \\
& Lelea, Terisi, Widasari, \\
$7-25$ & Jatibarang, Cikedung, \\
& Kertasemaya, Sukagumiwang, \\
& Bangodua, Tukdana \\
& Cikedung, Terisi, Kroya, \\
& Haurgeulis, Gantar
\end{tabular}

Airtanah

Akuifer bebas di Kabupaten Indramayu terletak pada kedalaman 3 - 30 $\mathrm{m}$ bawah muka tanah setempat. Komponen penyusun batuan pada akuifer terdiri dari pasir, pasir lempungan dan lempung pasiran, dengan perkiraan tebal akuifer bebas $15-20 \mathrm{~m}$.

Airtanah di Kabupaten Indramayu mengalir dari bagian Selatan ke Utara dari

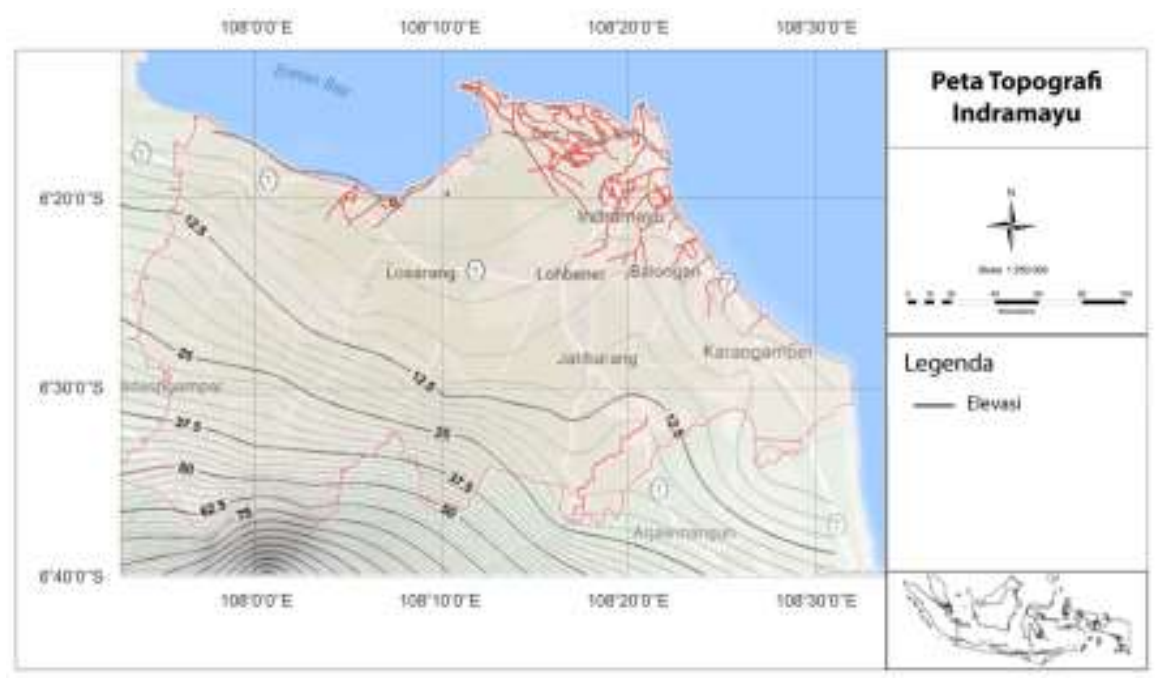

Gambar 2 Peta Topografi Kabupaten Indramayu (Geospasial BNPB, 2017)

Peta kontur Kabupaten Indramayu Gunung Tampomas menuju ke Laut Jawa. selengkapnya disajikan pada Gambar 2.

Berdasarkan hasil pengukuran pada 83 
titik, diperoleh hasil untuk kontur tinggi muka airtanah seperti pada Gambar 3.

Berdasarkan sebaran nilai TDS dan EC di bagian Utara Kabupaten Indramayu,
TDS dan EC berada di bagian selatan Kaupaten Indramayu sedangkan nilai tertinggi berada di bagian Utara yang merupakan daerah pantai. Berikut sebaran

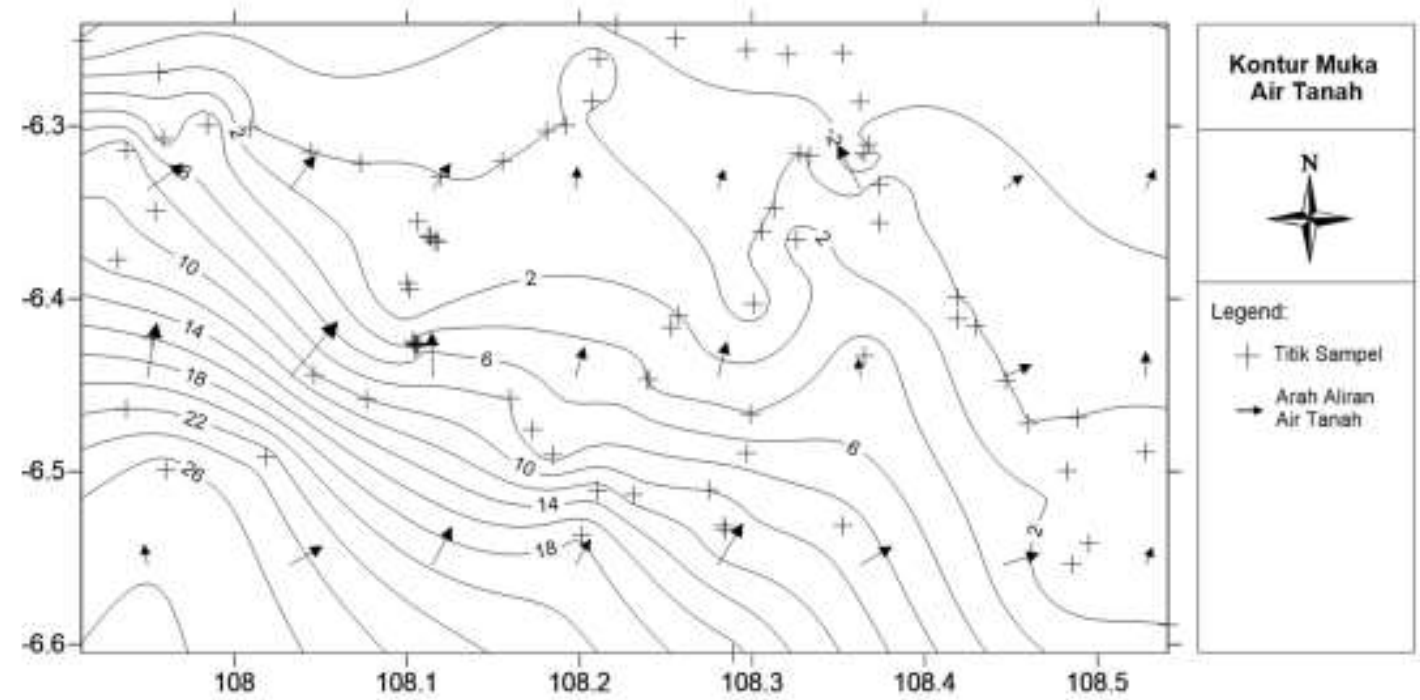

Gambar 3 Kontur Muka Airtanah Kabupaten Indramayu (hasil survey peneliti)

mengindikasikan bahwa airtanahnya telah tercemar air laut. Nilai TDS berkisar antara 203 ppm sampai dengan 4200 ppm. Nilai EC berkisar antara 256 ppm sampai titik sampling di Kabupaten Indramayu dapat dilihat pada Gambar 4.

\section{Prediksi Kualitas}

Menggunakan JST
Airtanah

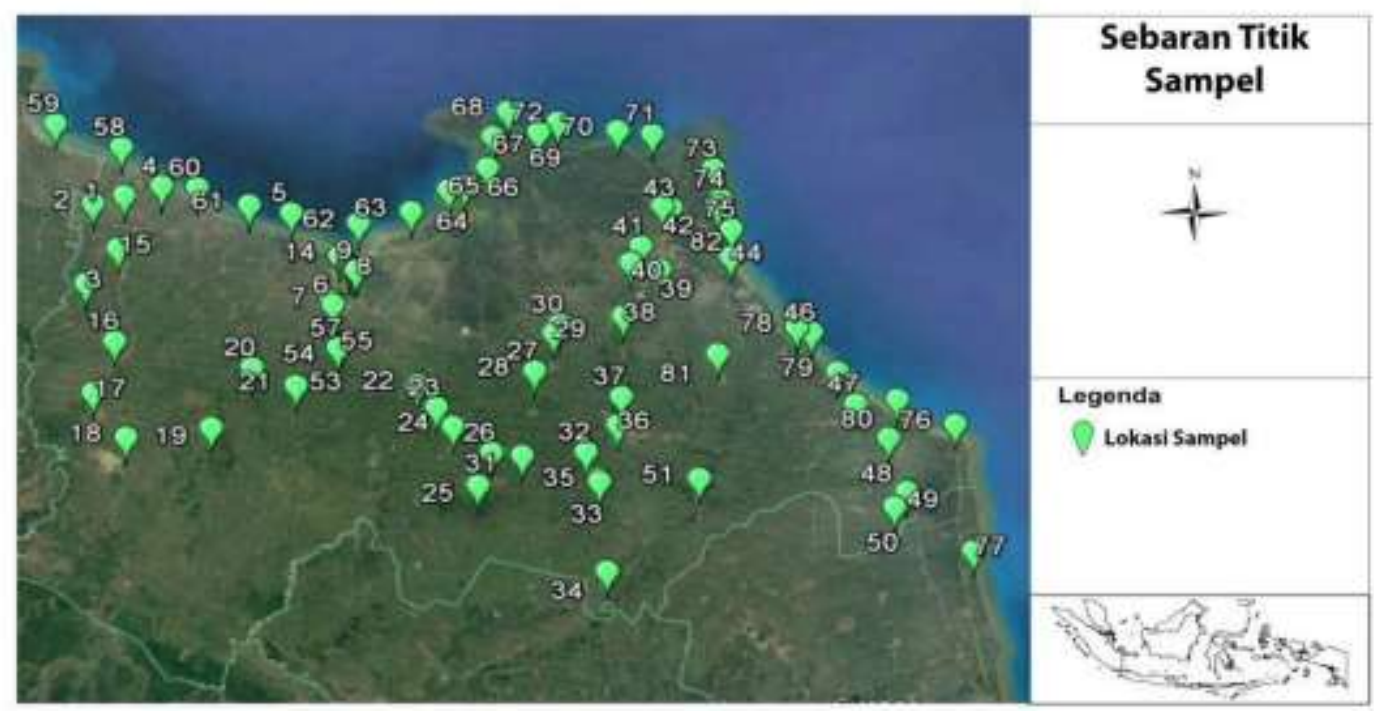

Gambar 4 Sebaran Titik Sampling Kabupaten Indramayu

dengan 5990 ppm. Nilai terendah dari 
Sebaran intrusi air laut kedalam airtanah dapat diprediksi meggunakan JST. Nilai yang menjadi input pada model JST meliputi nilai koordinat bujur, koordinat lintang, kedalaman dan elevasi. Kemudian hasil keluaran di output layer. Nilai output pada model JST meliputi nilai TDS dan EC. Berikut hasil prediksi metode JST dari persebaran titik sampel yang tersedia seperti ditunjukkan Gambar dengan mengacu pada nilai koefisien determinasi $\left(\mathrm{R}^{2}\right)$. Nilai $\mathrm{R}^{2}$ dari TDS 0.9104 dan EC sebesar 0.9069 dengan batasan nilai antara $0-1$. Jika nilai $\mathrm{R}^{2}$ mendekati 1 maka model JST dapat digunakan untuk nilai TDS dan nilai EC. Berikut kontur TDS dan EC pada Gambar 6.

Kontur TDS dan EC pada titik - titik sampel yang berada dibagian Utara dan

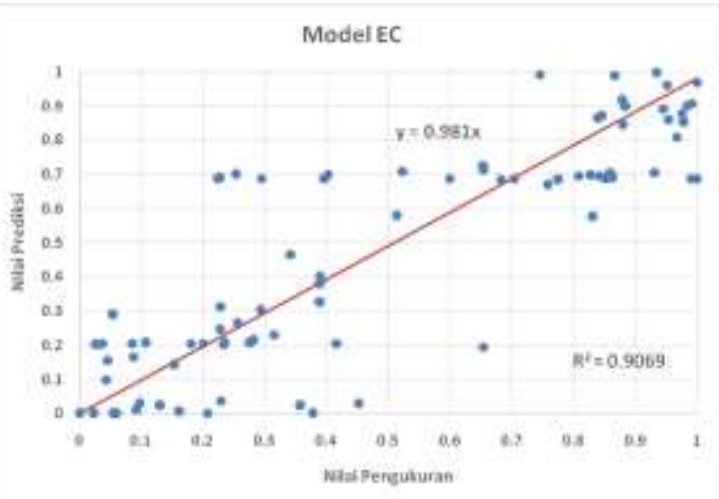

Gambar 5 Perbandingan Nilai Pengukuran dengan Nilai Prediksi

5.

Model JST memiliki nilai hasil pengukuran TDS dan EC dan membandingkan dengan nilai prediksi
Timur memiliki nilai yang lebih besar. Kemudian untuk batas nilai payau berdasarkan TDS berjarak sekitar $26.8 \mathrm{~km}$ dari pantai. Batas nilai EC berjarak $27 \mathrm{~km}$ dari pantai.
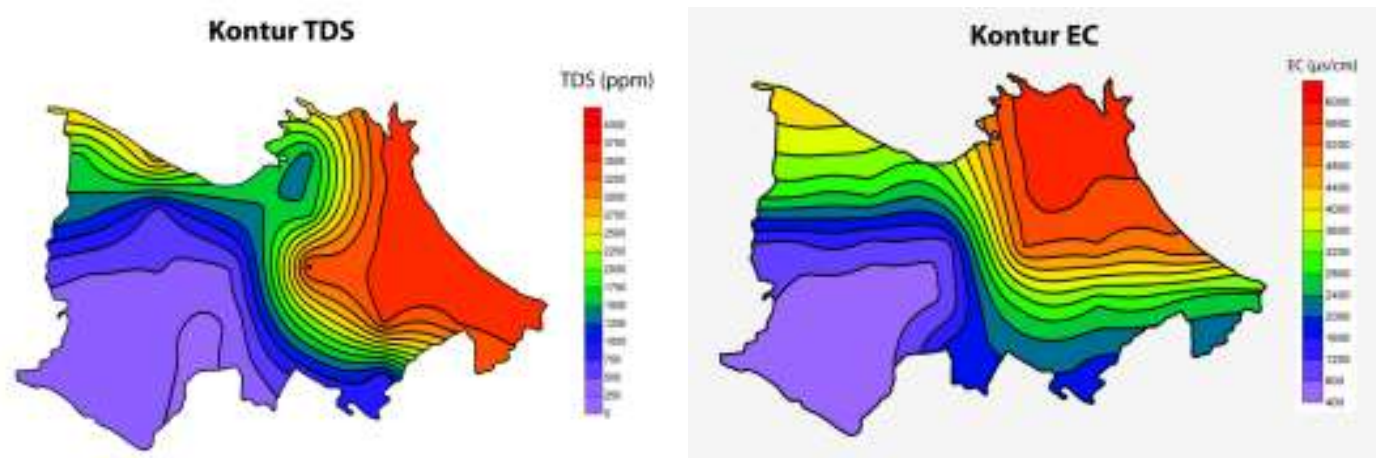

Gambar 6 Kontur TDS dan EC pada Kabupaten Indramayu 


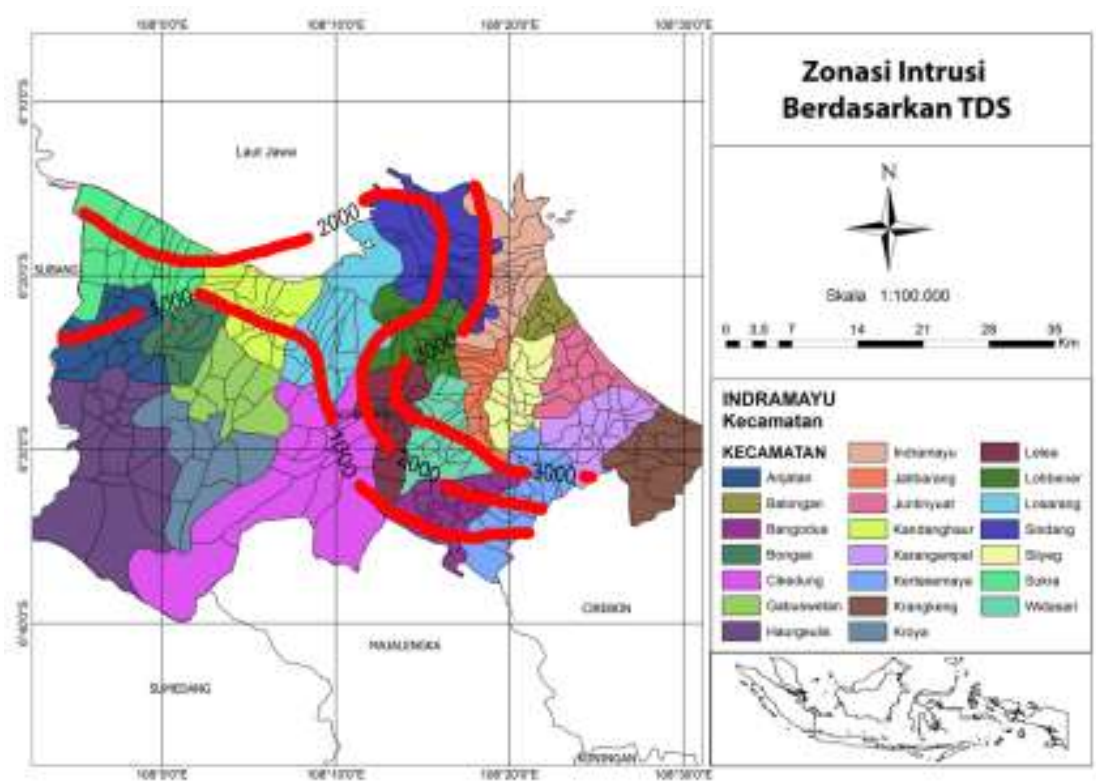

(a)

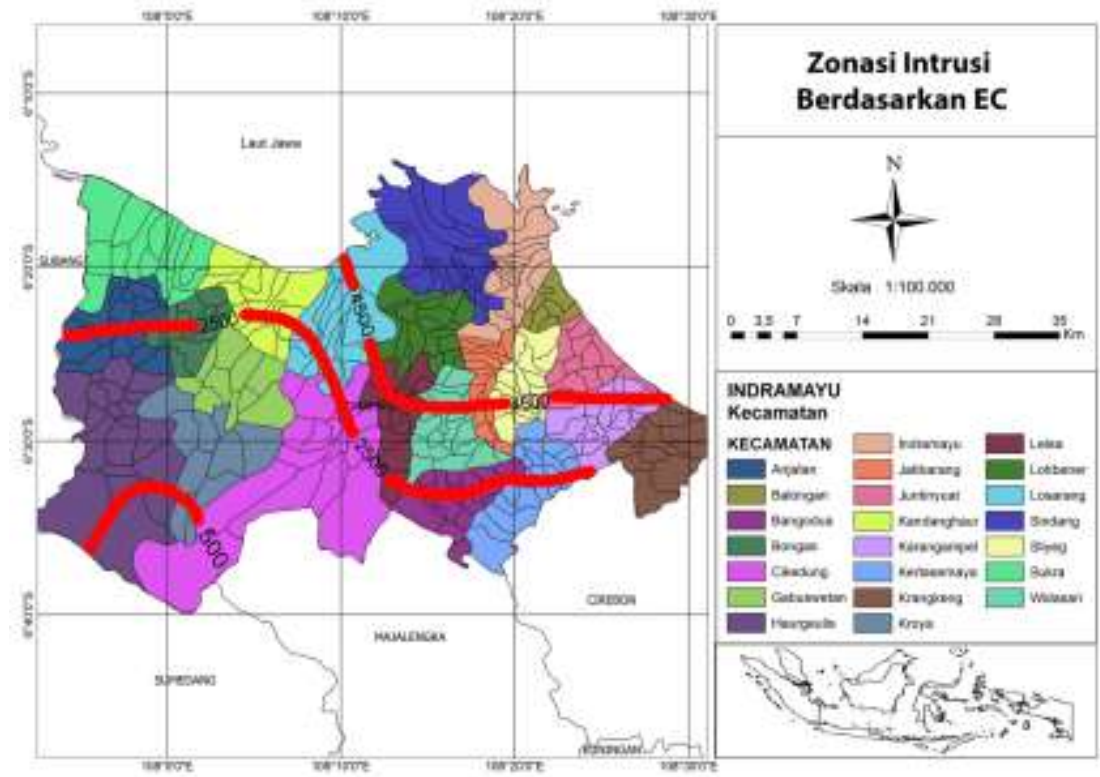

(b)

Gambar 7 Zonasi intrusi berdasarkan nilai, (a)TDS dan (b) EC

Berdasarkan klasifikasi nilai TDS sesuai peraturan PAHIAA, 1986 maka didapat bahwa batas payau untuk nilai TDS lebih dari 3000 ppm dan EC 5000 ppm. Nilai batas kontur digabungkan dengan peta administrasi agar didapat daerah yang di atas ambang batas yang telah ditentukan oleh PAHIAA, 1986.
Gambar 7 adalah zonasi intrusi berdasarkan nilai TDS dan EC.

Maka dapat disimpulkan bahwa Kecamatan Sukra, Bongas, Kandanghaur, Cantigi, Losarang, Sindang, Indramayu, Balongan, Jatibarang, Sliyeg, Juntinyuat, Kedokan Bunder, Karangampel, Lohbener, Arahan dan Krangkeng memiliki airtanah payau 


\section{KESIMPULAN}

Berdasarkan hasil penelitian pemetaan intrusi air laut berdasarkan kualitas airtanah di Kabupaten Indramayu, Jawa Barat dapat disimpulkan bahwa hasil pengolahan nilai TDS di daerah penelitian antara $361 \mathrm{ppm}$ sampai dengan $4081 \mathrm{ppm}$ dan nilai EC antara 491 ppm sampai dengan 5884 ppm dimana nilai TDS dan EC dibagian Utara relatif lebih tinggi dari bagian selatan Kabupaten Indramayu dimana nilai tersebut menunjukan bahwa di bagian utara Kabupaten Indramayu airtanah lebih payau.

\section{DAFTAR PUSTAKA}

Abarca E et al. 2007. Quasi - horizontal Circulation Cells in 3D Seawater Intrusion. Journal of Hydrology. 339.

Alimohammadlou Y, A Najafi, C Gokceoglu. 2014. Estimation of Rainfall-Inducted Landslides Using ANN and Fuzzy Clustering Methods: A Case Study in Saeen Slope, Azerbaijan Province, Iran. Catena 120: 149-162.

Amien ER. 2016. Analisis Pola Sebaran Curah Hujan Di Daerah Aliran Sungai Cisadane[Tesis]. Bogor (ID): Institut Pertanian Bogor.

Ayolabi EA, AF Folorunso, AM Ondukoya and AE Adeniran. 2013. Mapping saline water Intrusion into the Coastal Aquifer with Geophysican and Geochemical Techniques. Nigeria.

Bear J, A Verruijt. 1987. Modeling Groundwater Flow and Pollution. Netherlands. D Reidel. ISBN 155608-014-10: 1 - 13.

Effendi H. 2003. Telaah Kualitas Air Bagi Pengelolaan Sumberdaya dan Lingkungan Perairan. Yogyakarta (ID): Penerbit Kanisius.

Fausett L. 1993. Fundamentals of Neural Networks: Architecture, Algorithms and Applications. Prentice Hall.

Hendrayana H. 2002. Intrusi Air Asin ke

Dalam Akuifer di Daratan.

Yogyakarta (ID): UGM.

Herlambang A, RH Indriatmoko. 2005.

Pengelolaan Air tanah dan Intrusi

Air Laut. Jurnal Air Indonesia BPPT 1(1):88-98.

Hermantoro, Rudiyanto, S Suprayogi. 2008. Aplikasi Model Artificial Neural Network (ANN) dengan Geographycal Information System (GIS) untuk Elevasi Kesesuaian Lahan Perkebunan Kakao. Yogyakarta (ID). UGM Press.

Pemerintah Kabupaten Indramayu, 2011. Rencana Pembangunan Jangka Menengah Daerah Kabupaten Indramayu Tahun 2011 - 2015. Indramayu (ID): Kabupaten Indramayu.

Pemerintah Republik Indonesia, Dewan Perwakilan Rakyat dan Presiden Republik Indonesia. 2004. UndangUndang Nomor 7 Tahun 2004 Tentang Sumber Daya Air. Jakarta (ID): DPR dan Presiden RI.

Pradhan B dan S Pirasteh. 2011. HydroChemical Analysis of the Ground Water of the Basaltic Catchments: Upper Bhatsai Region, Maharastra. The Open Hydrology Journal, 2011, $5,51-57$.

Rudianto dan BI Setiawan. 2004. Backpropogation Artificial Neural Network (ANN) User's Manual. Bogor (ID). Institut Pertanian Bogor.

Sihwanto, Satriyo. 1991. Metode Penentuan Penyebab Keasinan Air tanah : Studi Kasus Daerah Dataran Pantai Dumai, Riau[Kumpulan Makalah Ikatan Ahli Geologi Indonesia]. Bandung(ID). Hal 2640.

Suhartono E, Purwanto, Suripin. 2012. Model Intrusi Air Laut Terhadap Air Tanah pada Akuifer di Kota 
Semarang. Semarang [ID]. Prosiding Seminar Nasional

Pengelolaan Sumberdaya Alam dan Lingkungan.

Todd DK.1980. Groundwater Hydrology $2^{\text {nd }}$ Edition. California (US): Jhon Willey \& Sons.

Waspodo RSB, P Irawan, SFD Saputra, AA Hafiidh. 2015. Kajian Hidrogeologi dan Sebaran Akuifer dengan Metode Tahanan Jenis (Geolistrik) di Desa Kedokan Gabus dan Desa Rancahan Kecamatan Gabus wetan Kabupaten Indramayu. Bogor[ID]. Institut Pertanian Bogor.

Werner AD, et al. 2013. Seawater Intrusion Processes, Investigation and Management: Recent Advance and Future Challenges. Adelaide (AU).

Widada S. 2007. Gejala Intrusi Air Laut di Daerah Pantai Kota Pekalongan. Jurnal Ilmu Kelautan ISSN 08537291. 12(1): 45-52. 